\title{
FURTHER STUDIES ON THE ANNEALING PROCEDURE FOR TLD-300
}

C. Furetta and J.W.N. Tuyn

CERN, 1211 Geneva 23, Switzerland

\begin{abstract}
This paper concerns the same experiments as those carried out to find the effect of various annealing procedures on the TL response of TLD-300. Different heating and cooling rates have been tried, and the effect of different atmospheres during annealing time has been tested.
\end{abstract}

To be submitted to Int. J. Appl. Radiat. Isot. 
In previous papers $[1,2,3]$ the dosimetric properties of thulium-activated calcium fluoride (TLD-300) have been reported. In a more recent work [4] the authors of the present one discussed the annealing procedures and their effects on the TL sensitivity of this phosphor. In that experiment the thermal treatments were carried out using a Vinten Annealing Facility, Model $622 / E$, where the heating from room temperature to the desired annealing temperature, as well as the cooling, are settled by the manufacturer.

In the same paper the optimum thermal treatment was claimed to be $400^{\circ} \mathrm{C}$ during 2 hours, in order to get the highest sensitivity possible, as well as the lowest threshold dose. On the other hand, it has been mentioned that different heating and cooling rates could change the sensitivity itself.

In the present paper some experiments have been carried out to test the effects of different heating-cooling rates on the TL sensitivity of $\mathrm{CaF}_{2}: \mathrm{Im}$, as well as the effect of different inert-gas atmosphere during annealing treatments.

EXPERIMENTS AND RESULTS

An annealing furnace having the possibility to flow in different gases has been used. Seven different thermal procedures have been carried out. A thermocouple was inserted in the dosimeter annealing stand to monitor the temperature during the heating and cooling rate.

The different procedures are as follows:

1. The dosimeters were put in the furnace at room temperature $\left(\sim 20^{\circ} \mathrm{C}\right)$ and then heated to $400^{\circ} \mathrm{C}$. This temperature was kept constant for two hours. At the end of the annealing time the furnace was switched off and the dosimeters were allowed to cool down from $400^{\circ} \mathrm{C}$ to $20^{\circ} \mathrm{C}$ in the furnace itself with the door closed. The heating rate was $6^{\circ} \mathrm{C} / \mathrm{min}$ and the cooling rate was $0.5^{\circ} \mathrm{C} / \mathrm{min} .$, approximately. 
2. The dosimeters were put in the furnace at room temperature and then heated to $400^{\circ} \mathrm{C}$. This temperature was kept constant for two hours. At the end of the annealing time the samples were taken out of the furnace and then cooled in air. The heating rate and the cooling rate were $6^{\circ} \mathrm{C} / \mathrm{min}$. and $4^{\circ} \mathrm{C} / \mathrm{min}$, respectively.

3. The dosimeters were put in the furnace (preheated to $400^{\circ} \mathrm{C}$ ), kept in this condition for two hours and then cooled in air outside the furnace. The heating rate was $15^{\circ} \mathrm{C} / \mathrm{min}$. and the cooling rate was $4^{\circ} \mathrm{C} / \mathrm{min}$.

4. The dosimeters were put in the furnace, (preheated to $400^{\circ} \mathrm{C}$, and filled with argon), kept in these conditions for two hours and then cooled in air outside the furnace. Heating and cooling rates as before.

5. The dosimeters were put in the furnace (preheated to $400^{\circ} \mathrm{C}$ ) and filled with helium. After two hours in these conditions the dosimeters were cooled in air outside the furnace. Heating and cooling rates as before.

6. The dosimeters were put in the furnace (preheated to $400^{\circ} \mathrm{C}$ ) and filled with helium. After two hours of thermal treatment the furnace and the gas flow were switched off and the cooling took place with the samples in the open-door furnace and a forced-air ventilation. Heating rate as before and cooling rate at about $1.5^{\circ} \mathrm{C} / \mathrm{min}$.

7. The dosimeters were put in the pre-heated furnace $\left(400^{\circ} \mathrm{C}\right)$ and filled with helium. The annealing procedure at $400^{\circ} \mathrm{C}$ took place and at the end of the two-hour treatment the heating and the gas flow were switched off. The cooling took place in the furnace with the door closed and with a forced-air ventilation. Heating rate as before and cooling rate at about $1.2^{\circ} \mathrm{C} / \mathrm{min}$. 
At the end of the seven previously mentioned procedures the first procedure was repeated one more time to check the recovery of the initial properties of the TL material. After each thermal treatment the TLDs received a $\beta$ dose of $16.7 \mathrm{mGy}\left(\mathrm{Sr}^{90}-\mathrm{Y}^{90}\right)$ and were read out immediately. The profiles for each thermal treatment are plotted in Fig. 1. The heating and cooling rates are also reported in this figure.

Ten dosimeters, always the same, were used for all the experiments; in that way each experimental point represents the average of ten observations with an error equal to 10 .

In Fig. 2 are reported the data obtained from the experiment. All the data are normalized to the one concerning the first procedure. The data concern peaks 2,3 and 5 and they are given as peak height $\left(\mathrm{H}_{i}\right)$, peak area $\left(\phi_{i}\right)$, total glow-curve area $\left(\phi_{T}\right)$ and sensitivity (nC/mGy).

As one can see in Fig. 2 the data decrease from 1 to 7 . It seems evident that the first procedure with a very slow cooling rate is the best. Slow cooling of TLD-300 causes the heights and the areas of all the peaks in the glow curve to be higher than for rapid cooling and therefore a slow heating rate seems to be better than a fast one. A slow cooling may stabilize the distribution of the traps.

On the other hand, an annealing atmosphere of argon or helium does not seem to have any drastic effect on the TL response. Comparing the total light in the first procedure with that in the 7 th one, a $10 \%$ difference may be observed. A larger difference may be observed for the peak height, while the peak area seems to be less affected. These reductions are not dramatic lacks, but they could become important when the material is used in a very low-dose level, i.e. in environmental dosimetry; in fact the sensitivity shows a $10 \%$ difference between the first and the seventh procedure.

The glow curves do not present evident differences in shape and the peak positions remain the same. Generally, different annealing procedures do not seem to affect substantially the structure of the glow curve. These results confirm the one obtained in a previous paper on the annealing procedures for this material [4]. 
From Fig. 2 can be observed that the 8 th procedure, the same as the first one, allows a recovery of the initial conditions.

As a conclusion it is possible to confirm that the annealing procedures do not affect strongly the characteristics of the glow emission and only in particular cases of application, where very low doses are involved, a particular attention is needed in the annealing treatment to allow a good reproducibility and high sensitivity.

\section{ACKNOWLEDGEMENT}

We thank Dr. F. Ferger for his useful suggestions concerning this work and Mr. B. Trincat for carrying out the thermal treatments. 


\section{REFERENCES}

1. Furetta C. and Lee Y.K., Radiat. Protect. Dosim. 5, 57 (1983.

2. Furetta C. and Lee Y.K., Radiat. Protect. Dosim. 11, 101 (1983).

3. Furetta C., Tuyn J.W.N., and Lee Y.K., Int. J. Appl. Radiat. Isot. In press (MS 667) (1985).

4. Furetta C. and Tuyn J.W.N., Int. J. Appl. Radiat. Isot. In press (1985). 
FIGURE CAPTIONS

Fig. 1 Profiles of different thermal treatments.

Fig. 2 Results obtained using different treatments:

from (a) to (c): peak heights,

from (e) to $(g)$ : peak areas,

(d): total glow-curve areas

(h) sensitivity ( $\mathrm{nC} / \mathrm{mGy}$ ) 


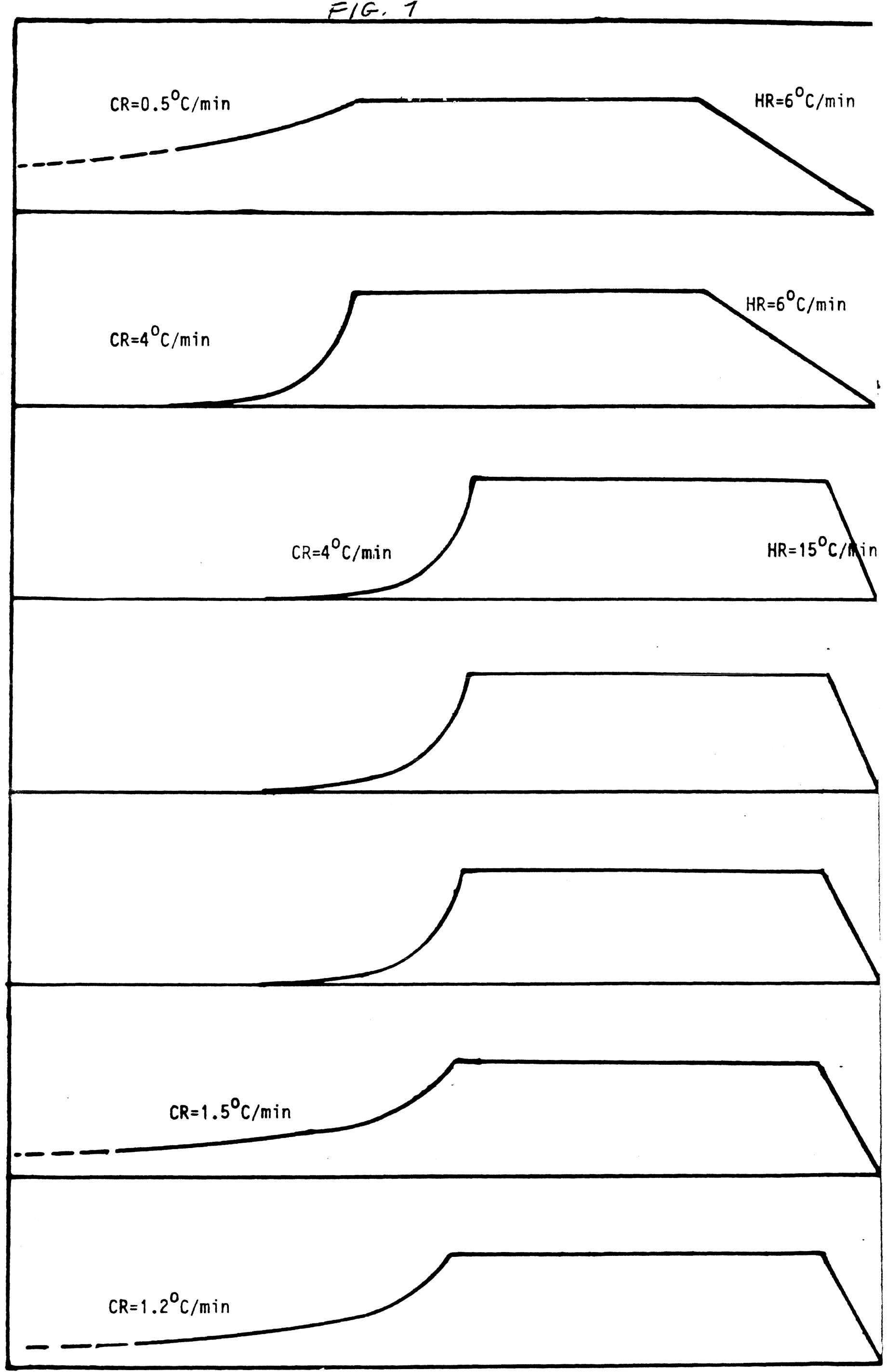


$F / G .2$

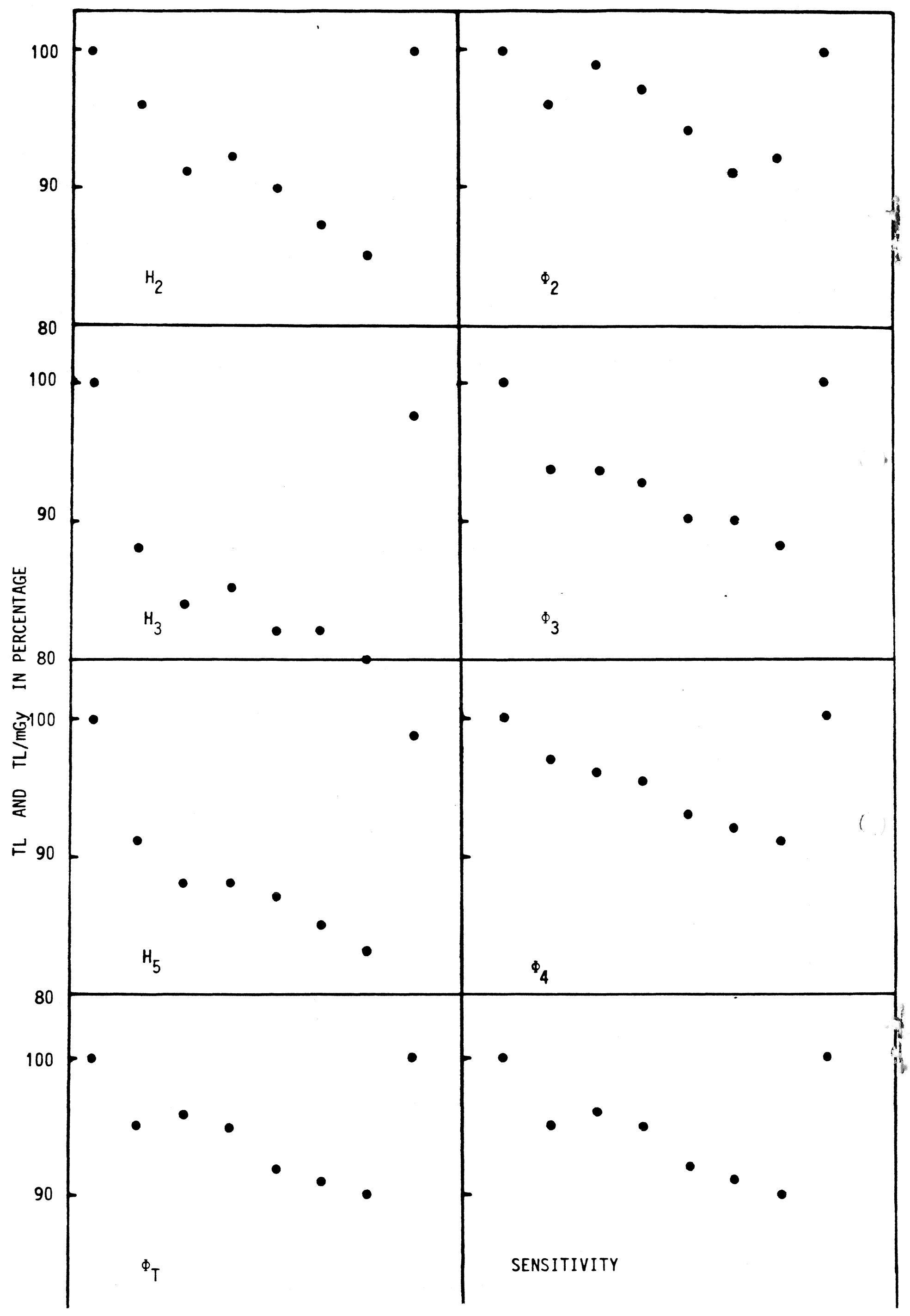

